\title{
Optics and optronics in university courses for officers of the Federal Armed Forces - special curricula and hands-on lessons vs. academic requirements
}

Cornelius Hahlweg, Hendrik Rothe

Cornelius Hahlweg, Hendrik Rothe, "Optics and optronics in university courses for officers of the Federal Armed Forces - special curricula and hands-on lessons vs. academic requirements," Proc. SPIE 9946, Optics Education and Outreach IV, 99460J (27 September 2016); doi: $10.1117 / 12.2238055$

SPIE Event: SPIE Optical Engineering + Applications, 2016, San Diego, California, United States 


\title{
Optics and optronics in university courses for officers of the Federal Armed Forces - special curricula and hands-on lessons vs. academic requirements
}

\author{
Cornelius Hahlweg ${ }^{a, b}$ and Hendrik Rothe ${ }^{a}$ \\ ${ }^{a}$ Helmut Schmidt University - University of the Federal Armed Forces Hamburg \\ Holstenhofweg 85, D-22043, Germany \\ ${ }^{b}$ bbw Hochschule - University of Applied Sciences \\ Leibnizstrasse 11-13, D-10625 Berlin, Germany
}

\begin{abstract}
For more than two decades lessons in optics, digital image processing and optronics are compulsory optional subjects and as such integral parts of the courses in mechanical engineering at the University of the Federal Armed Forces in Hamburg. They are provided by the Chair for Measurement and Information Technology. Historically, the curricula started as typical basic lessons in optics and digital image processing and related sensors. Practical sessions originally concentrated on image processing procedures in Pascal, C and later Matlab. They evolved into a broad portfolio of practical hands-on lessons in lab and field, including high-tech and especially military equipment, but also homemaker style primitive experiments, of which the paper will give a methodical overview. A special topic - as always with optics in education - is the introduction to the various levels of abstraction in conjunction with the highly complex and wide-ranging matter squeezed into only two trimesters - instead of semesters at civil universities - for an audience being subject to strains from both study and duty. The talk will be accompanied by striking multi-media material, which will be also part of the multi-media attachment of the paper.
\end{abstract}

Keywords: military, mechanical engineering, trimester, dual program, optics, image processing, personal stress and pressure, education

\section{Introduction}

The paper - unlike the many technical manuscripts we presented over the last two decades - is dedicated to a more non-technical, organizational and social subject: conducting university courses in optics and optronics for students who are integrated not only in their university program, but also in an extremely demanding professional environment. In our case, these are young officers of the Federal Armed Forces of Germany, studying mechanical engineering at the Helmut-Schmidt-University Hamburg. A short discussion of the time line of their education and the subjects the program is based on, reveals the conflicts between academic demands, hands-on education needs and compact structure of the university programm, which are arising for the Department of Measurement and Information Technology. As a consequence, the evolution of the optronics courses shows a convergence with subjects such as defense technology and ballistics. The academic education of officers is not the only case in which the students are exposed to the high stress caused by a dually interacting environment, consisting of university program and an employer. The transition of the optronics course concept to a dual bachelor course in electrical engineering at the bbw Hochschule Berlin shows similar interesting effects, which shall be discussed in short.

Further author information: CH: cornelius.hahlweg@bbw-hochschule.de, HR: rothe@hsu-hh.de 


\section{Academic education in the Federal Armed Forces}

The career of the officers of the German Federal Armed Forces, demands an academic degree. The necessary academic programs for the majority of the officers are conducted at two dedicated universities of the Federal Armed Forces. The subjects do not necessarily correlate with the later disposition in the forces. About half of every year's young officers study at the Helmut Schmidt* University University of the Federal Armed Forces Hamburg. The HSU offers a full variety of subjects, from economics, over history, social sciences, to engineering.

After secondary school and about 1 year of basic military training the young officers, who are committed to 12 years of military service, are facing a compact academic program:

- The academic year divided into 3 trimesters.

- Bachelor and Master programs are conducted as consecutive programs.

- The full time Bachelor programs starts every year in October and have a duration of 7 trimesters, which is 2 years and 3 months.

- The full time Master programs last start in January with a duration of 5 trimesters, which is 1 year and 9 months.

The students live on campus and in close surrounding, most of the time they act like civil persons, and so the university acts like any civil university ${ }^{\dagger}$.

\section{Mechanical Engineering program at the HSU}

The HSU offers consecutive engineering programs in both electrical and mechanical engineering. The Chair for Measurement and Information Technology is part of the Department for Mechanical Engineering, thus being responsible for the basic courses in Informatics and Metrology for the Bachelor program in mechanical engineering, which both are accompanied by extensive lab practice. Further, their responsibility includes the higher courses for ballistics, optronics, defense and ammunition technology and micro-controller engineering during the mechanical engineering Master program. The optronics course shall be subject to further discussion.

To understand the approach of the optronics course, a look into the curricula of the mechanical engineering consecutive program is useful. The following list covers the full program, only the subjects are excerpted:

\begin{tabular}{|l|l|}
\hline Basic Internship & Internship \\
Applied Computer Science I & Technical Drawing / CAD \\
Chemistry & Mathematics I \\
Materials Technology & Mechanics I and II \\
Mathematics II and III & Laboratory \\
Machine Elements I and II & Thermodynamics I and II \\
Process Data Processing & Production Engineering \\
Dynamics of Machinery I & Metrology \\
Fluid Mechanics I & Numerical Mathematics I \\
Modeling of Mechanic Systems & Methods of Systems Development \\
Automation & Applied Computer Science II \\
Computational Methods & Heat Transfer I \\
Propulsion Techniques & Electrical Engineering \\
Language Courses during Officer Training & Language Courses during Study \\
Interdisciplinary Courses & Bachelor-Thesis \\
\hline
\end{tabular}

Obviously this is the typical curriculum for a mechanical engineering Bachelor program, only one has to keep in mind that this is conducted in 2 years and 3 months with very low tolerance in the time line, which means the academic follows the military timing, especially there is little space for any extensions.

The Master program offers the special sub-programs

\footnotetext{
*Named after Helmut Schmidt, 1918 - 2015, former chancellor of the FRG 1974 -1982.

${ }^{\dagger}$ For extensive information visit www.hsu-hh.de .
} 
- Energy and Environmental Engineering

- Mechatronics

- Applied Mechanics

- Defense Technology

- Product Design and Logistics,

of which only Mechatronics and Defense Technology shall be considered here, due to their inclusion of the Optronics course.

To give a further overview on the Master program, we extracted only the compulsory subjects, and the compulsory elective subjects which are fundamental for the Optronics course ${ }^{\ddagger}$.

\begin{tabular}{|l|l|}
\hline Compulsory subjects & \\
Interdisciplinary Courses & Principles of Product Development \\
Mechanics III (Intr.to Comp. Mechanics) & Dynamics of Machinery II \\
Introduction to Mechatronics & Fluid Mechanics \\
Thermodynamics III & Advanded Heat and Mass Transfer \\
Mathematics IV & Study Project \\
Consolidating Practical Training & Cons. Pract. Training in Automotive Engineering \\
& \\
Compulsory elective subjects & Technical Electronics I+II \\
Systems Identification I+II & comment: transferred to another chair for mechatronics \\
Image Processing & comment: micro-controller technology \\
Informatics III & 2 trimesters, optronics course, in German 'Optronik' \\
Electro-Optics & 1 trimester, first part of Optronik, formerly Image Processing \\
Electro-Optics I & Weapony and Ammunition Technique \\
Ballistics & \\
Master-Thesis & \\
\hline
\end{tabular}

We see that the academic background necessary for extensive Optronics is delivered with certain compulsory elective subjects, such as Systems Identification and Technical Electronics. Although the contents might not reach the level one would expect in a comparable electrical engineering course, usually they tend to proof to be sufficient. Certain basics, as for instance Fourier theory, have to be repeated and extended during the course.

\section{Evolution of the Optronics course}

Figure 1 illustrates the evolution of the Optronics course over three decades. Initially, a course in digital image processing with theoretical lectures and a PC lab part based on C routines and a theoretical course in optics were conducted. Over the years, basics on sensors optics were included into the image processing course, due to the fact that students not necessarily had to choose the optics course, too. On the other hand, military technology was included in the optics course to meet the demands of the officers. The annual night vision hands-on event, in which the students could use state of the art technology, moved from the sports ground of the HSU on late evenings to - due to earlier sunset - wintertime full day sessions at an outdoor shooting range.

These night vision excursions were conducted with real shooting sessions using original gear. Gaining interest by students and the introduction of high speed video technology at the MIT chair triggered the combination with the Ballistics and Ammunition courses, which lead to extended multi-day sessions at an in-door shooting range, were high-speed video technology could be experienced beside special ballistic instructions.

The Image Processing course switched to Matlab based PC lab sessions, which lead to better focus on the principle methods due to easier visualization. Around that time we introduced lab sessions practical applications such as metrological image processing. Also optics and opto-electronics became part of the lab sessions. When

\footnotetext{
${ }^{\ddagger}$ Below the original English time table entry 'Electro-Optics'.
} 


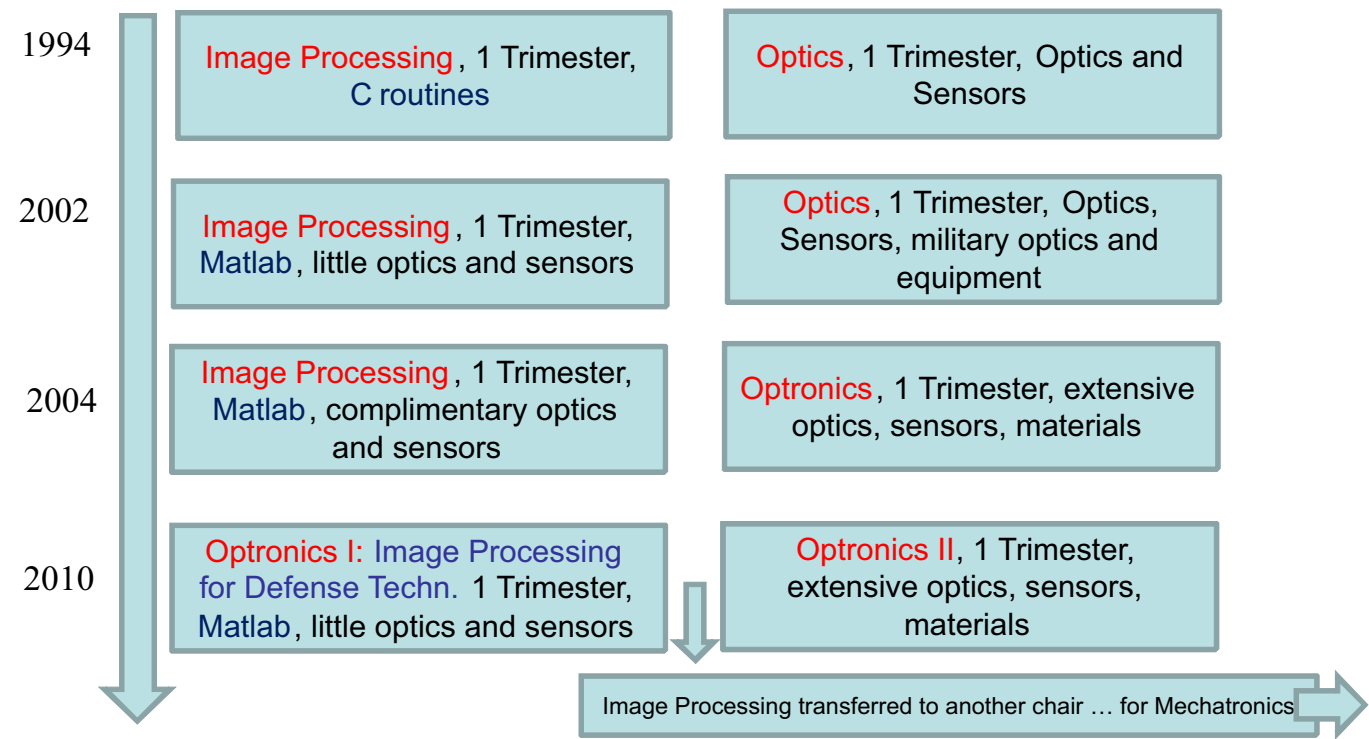

Figure 1. Evolution of the Optronics course: a rough time bar.

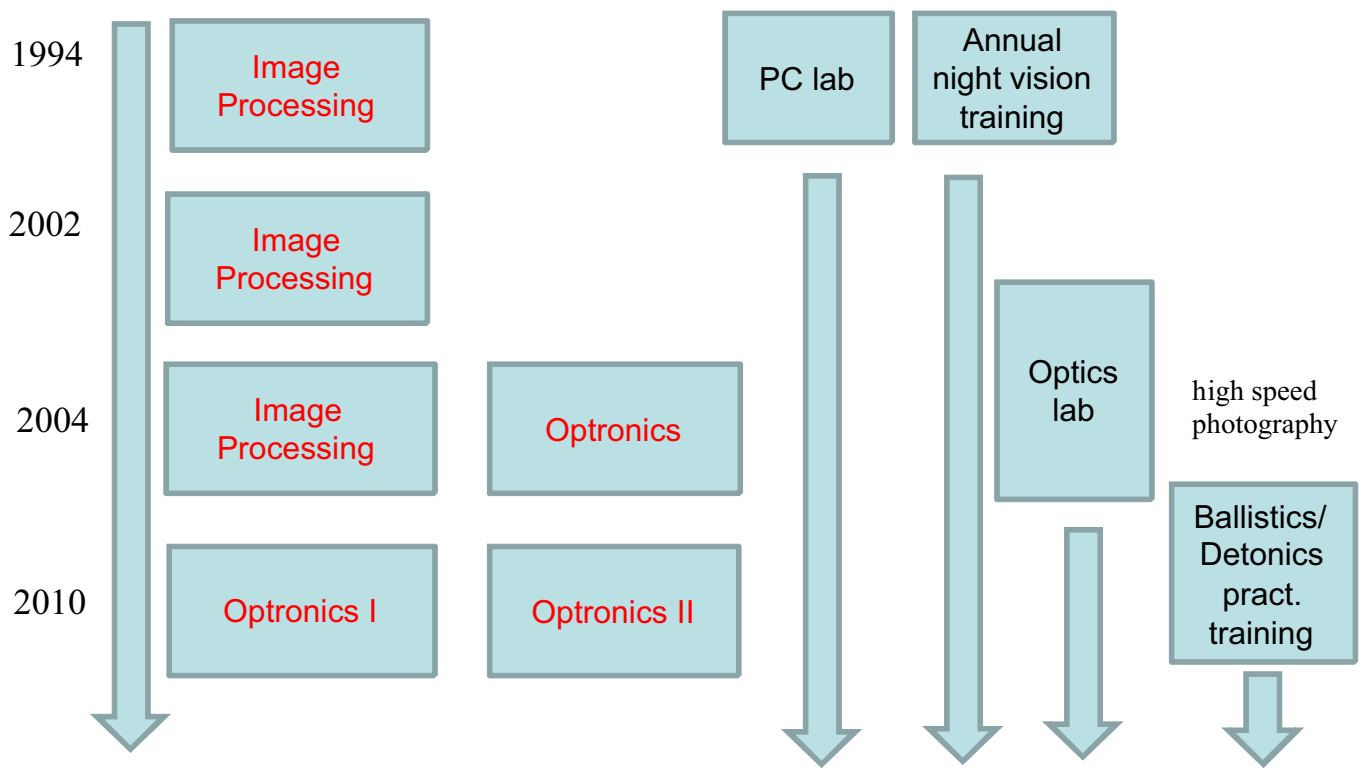

Figure 2. Convergence with other subjects and practical extensions: Lab, hands-on, fusion and crossover activity. 
an analogue CCD cam is used with a monitor screen, the composite video signal is observed using an oscilloscope, and finally a CCD element is assembled from a photodiode and a capacitor and illuminated while the capacitor voltage is checked on the oscilloscope.

Later on the Image Processing and the Optics courses were merged under the names Optronics I+II, due to the fact that an Image Processing course was claimed by another chair for the Mechatronics branch of the Master program. Soon it turned out that Optronics I and Image Processing for Mechatronics had a very different philosophy and were more of a complimentary pair, so many students ended up choosing both courses.

\section{Complexity vs. academical background vs. hands-on practice}

What can we expect to put into only two trimesters of Optronics, which is optics, photonics, systems theory, signal and image processing, materials and physical basics? There are several hard boundary conditions to be taken into account.

- Obviously, the mechanical engineering program lacks certain specific background topics an electro-engineering course would deliver naturally.

- The whole academic course is extremely compact.

- The students are permanently under high pressure from both academic and professional demands.

- What to focus on without sacrificing academic claims?

- How to keep the fun in it after all?

The answers are as natural as pragmatical:

1. The curriculum consists of a reduced but precise set of basics which might be practically experienced: everything should be practicable in the Lab at least in a primitive waxy to leave persistent impressions. If it can be done, they should experience that. A typical example from the night vision training demonstrates the difference between cooled and uncooled IR sensors by using two thermal imaging devices, looking at each others aperture: the cooled sees the uncooled like a head light; in general, debunking IR myth is essential for soldiers.

2. We go through the set of basics iteratively on constantly increasing levels; for the beginner this seems to be a vast number of facts without any systematics, which is then to be overcome by practical lab and field experience. An example from Optics:

- Do the simple paraxial construction for the lens they gave you;

- Try and measure.

- Build a lens from a water filled watch glass, try and measure, apply matrix method to determine radius of the glass.

3. Force them to develop, analyze and/or investigate at least one object on their own, including math and experimental design:

- reduces fear of the complicated stuff they study, not only in optics;

- enables them to act self-reliant in other courses.

- If it works for only $20 \%$ of the students, the mission might be fulfilled.

4. Always give them something they might actually use further on.

- Image Processing delivers a set of useful Matlab scripts, which often end up in work for other departments. 
- Choosing the tight lens and camera cannot be overrated.

- To know what thermography actually is capable of, and what would never work, will save every homeowners money, at least in Germany.

5. Final examination is conducted as a 45 minutes oral colloquium. A loose conversation, starting with whatever they choose from the hands-on material box put on the table. The cause of its bad reputation among the students is unknown. No one ever finally flunked. The questions are developed during the examination, but always on subjects the students had experienced practically.

6. Giving perspective of interesting practically oriented topics for Bachelor and Master thesis in a well known environment with good support by assistants and mechanical workshop.

7. Integration of student projects into the course leads to consistency of recruitment, is building a whole community and further reduces fears.

Figure 3 shows still images from footage which was recorded during combined hands-on sessions ${ }^{\S}$. As one might see, there is essential experience for the soldier, such as the myth of the handgun which should explode when fired under water, but also the funny side of life.
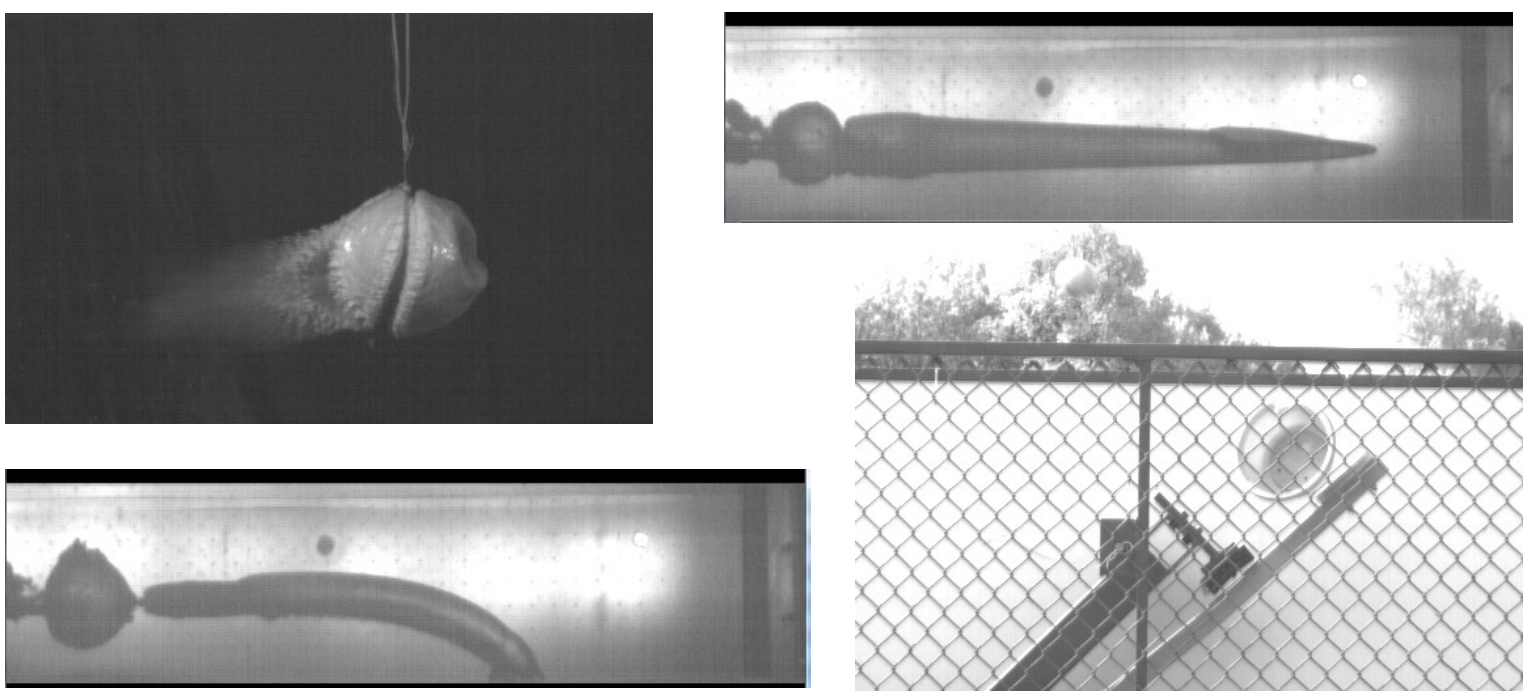

Figure 3. Still images of typical footage from such educational sessions with integrated student projects. Upper left: balloon with corn starch. Upper right: firing a Makarov $9 \mathrm{~mm}$ under water, original projectile. Lower left: Makarov underwater, less successful modified projectile. Lower right: a special pneumatic ballistic machine, less successful. The videos are attached to the electronic version of the paper.

\section{Transition to dual program in electrical engineering}

In 2013 bbw Hochschule Berlin started a dual bachelor program in electrical engineering for Deutsche Bahn AG, a major German logistics provider $\pi$. The program is designed for a 6 semester duration with the students alternating between university and their working places in 3 month periods. While the design of the courses already showed the need for extreme compactness, soon after the first semester started, it turned out that there are other clear similarities and parallels to the HSU students in terms of the dual demands they are exposed

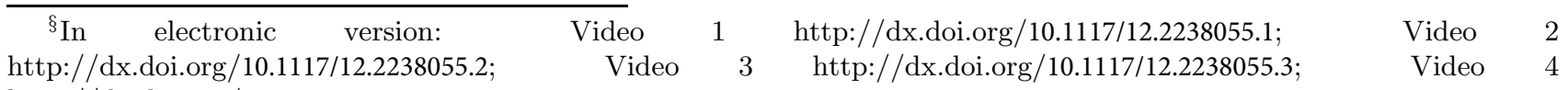
http://dx.doi.org/10.1117/12.2238055.4.

${ }^{\top}$ For further information visit www-bbw-hochschule.de . 
to. The curriculum contains a course in Optics and Opto-electronics, which is conducted parallel to a course in RF technology. Beside their theoretical content - due to the academic background after 4 semesters of Electrical Engineering less problematic than in the case of Mechanical Engineering - both courses merge into combined hands-on sessions after half a semester. For the final examination student projects are developed out of these sessions, thus avoiding written exams, which usually lead to excessive learning overhead and zero sustain. Meanwhile, the first run finished their Bachelor theses successfully, some of which actually base on topics from the Optics and RF lessons.

\section{Conclusion and outlook}

An insight into special educational problems arising with the conduction of demanding courses like optics and optronics under the special conditions academic courses addressing of military and dual students was given.

The experiences of over three decades resulted in the development of special concepts, which might be useful in similar situations and not only for optics.

It should be emphasized that the inclusion of the students into the research activities is also documented in a series of SPIE papers, from $\mathrm{HSU}^{1-5}$ as well as from $\mathrm{bbw}^{6-10}$ and also in collaboration. ${ }^{11}$

\section{REFERENCES}

1. Hahlweg, C., Skaloud, D., Gutzmann, H., Kutz, S., and Rothe, H., "Visualization of sound generation - special imaging techniques," Novel Optical Systems Design and Optimization XVI Proceedings of SPIE Proceedings of SPIE 8842-16, 2013.

2. Hahlweg, C., Weyer, C., Gercke-Hahn, H., Gutzmann, H., Brahmann, A., and Rothe, H., "Perception of power modulation of light in conjunction with acoustic stimulation," Novel Optical Systems Design and Optimization XVI Proceedings of SPIE Proceedings of SPIE 8842-17, 2013.

3. Hahlweg, C., Zhao, W., Vogeler, H., and Rothe, H., "Imaging of short time microscopic scenes with strong light emission: revisited," Instrumentation, Metrology, and Standards for Nanomanufacturing, Optics, and Semiconductors VI Proceedings of SPIE 8466, 2012.

4. Hahlweg, C., Wilhelm, E., and Rothe, H., "Laser based imaging of time depending microscopic scenes with strong light emission," Instrumentation, Metrology, and Standards for Nanomanufacturing, Optics, and Semiconductors V Proceedings of SPIE 8105, 2011.

5. Wilhelm, E., Chalupka, U., Hahlweg, C., Zhao, W., and Rothe, H., "A stereoscopic imaging system for laser back scatter based trajectory measurement in ballistics," SPIE-7792-23 , 2010.

6. Dannenberg, F., Pescoller, L., Weiß, J., and Hahlweg, C., "A rugged stereoscopical device for surface inspection," Applied Advanced Optical Metrology Solutions Proc. SPIE. 9576, 2015.

7. Dannenberg, F., Uebeler, D., Weiß, J., and Hahlweg, C., "Extended volume and surface scatterometer for characterization of 3d-printed objects," Optomechanical Engineering 2015 Proc. SPIE. 9573, 2015.

8. Uebeler, D., Pescoller, L., and Hahlweg, C., "Further development of imaging near-field scatterometer," Novel Optical Systems Design and Optimization XVIII Proceedings of SPIE Proc. SPIE. 9579, 2015.

9. Dannenberg, F., Hahlweg, C., Pescoller, L., and Zhao, W., "Near-field imaging techniques for surface inspection," Novel Optical Systems Design and Optimization XVII Proceedings of SPIE Proc. SPIE. 9193, 2014.

10. Hahlweg, C., Dannenberg, F., Dörfler, J., Weber, B., Weyer, C., Gercke-Hahn, H., Heucke, S., Freimuth, S., and Gutzmann, H. L., "Chords and harmonies in mixed optical and acoustical stimuli," Novel Optical Systems Design and Optimization XVII Proceedings of SPIE Proc. SPIE. 9193, 2014.

11. Kleebereg, F.P., Gutzmann, H. L., Weyer, C., Weiß, J., Dörfler, J., and Hahlweg, C., "Investigation of correlation of lf power modulation of light in natural and artificial illumination situations and acoustic immission," Thirteenth International Conference on Solid State Lighting Proc. SPIE. 9190, 2014. 